\title{
OS IMPACTOS AMBIENTAIS NA REGIÃO DO PONTAL DO PARANAPANEMA NA PERSPECTIVA HISTÓRICA
}

Graziella Plaça Orosco de Souza, Munir Jorge Felício

Universidade do Oeste Paulista - UNOESTE. E-mail: graza@unoeste.br

\section{RESUMO}

Este trabalho tenciona compreender de que forma vem sendo divulgada a história dos impactos ambientais na região do Pontal do Paranapanema. Tendo como referenciais teóricos diversos historiadores e sociólogos, como também pesquisadores que se dedicaram à análise regional. 0 texto deverá considerar a divulgação das informações referentes aos impactos ambientais ocasionados principalmente pelo avanço capitalista à região, com a implantação e funcionamento das usinas hidrelétricas e dos empreendimentos movidos pelo agronegócio sucroalcooleiro na década de 1990. Almeja verificar as interpretações contidas nas informações divulgadas. Por se tratar de uma discussão historiográfica, torna-se oportuno o presente estudo sobre a região do Pontal do Paranapanema que já vem sendo amplamente estudada na perspectiva geográfica, política, social e econômica e, poderá também ser objeto de análises históricas do ponto de vista ambiental.

Palavras-chave: Divulgação e interpretação. Perspectiva histórica. Impactos ambientais. Meio Ambiente.

\section{INTRODUÇÃO E OBJETIVO}

A História como uma das Ciências Sociais Aplicada desenvolve suas atividades construindo e reconstruindo as interpretações dos sinais evolutivos registrados pela humanidade. Esses registros de transformações sociais, econômicas, políticas e culturais fazem com que o ser humano seja protagonista ao apropriar-se desta historicidade a qual ultrapassa o movimento cíclico temporal. A História, nesta perspectiva, cumpre a função de fazer emergir conhecimentos e gerar cada vez mais a consciência desse agente transformador social.

Uma vez que a história da humanidade é reconstituída principalmente através de documentos escritos deixados por pessoas contemporâneas aos fatos, a racionalidade torna-se a ferramenta mais importante do historiador, por ser ela que o auxilia nas análises sobre a realidade dos fatos. Portanto, o fato histórico não é um elemento dado e acabado, mas resultado da reflexão do historiador. Neste contexto porque sempre se tem a impressão de que a História é contada pelos vencedores?

Esta questão pode ser respondida por meio do conceito de estratificação social, inerente à sociedade humana organizada desde seus primeiros agrupamentos sociais. A estratificação social seja ela econômica, política, profissional, sempre segregará baseada em graus de importância: o 
rico é mais importante que o pobre, o grupo que tem poder é mais importante que o que não tem; o intelectual é mais respeitado que o ignorante. Esta leitura capitalista das relações de poder e de como são interpretadas e discutidas as informações históricas, podem ser verificadas em Max Weber (1997). Para o autor,

O homem é dominado pela produção de dinheiro, pela aquisição encarada como finalidade última da sua vida. A aquisição econômica não mais está subordinada ao homem como meio de satisfazer suas necessidades materiais. Esta inversão do que poderíamos chamar de relação natural, tão irracional de um ponto de vista ingênuo, é evidentemente um princípio orientador do capitalismo, tão seguramente quanto ela é estranha a todos os povos fora da influência capitalista (WEBER, 1997, p. 33).

Huberman (1979) tenta explicar, em termos de desenvolvimento das instituições econômicas, por que certas doutrinas surgiram em determinado momento, como se originaram na própria estrutura da vida social, e como se desenvolveram, modificaram e foram ultrapassadas, ao mudarem os padrões daquela estrutura.

Tratando dos bens mundanos do ser humano, Huberman reuniu em duas partes o que ele denominou de "História da Riqueza do Homem". Na primeira parte ele procura compreender como se deram as transformações da sociedade feudal para a sociedade capitalista. "A sociedade feudal consistia dessas três classes - sacerdotes, guerreiros e trabalhadores - sendo que o homem que trabalhava produzia para ambas as outras classes, eclesiástica e militar" (HUBERMAN, 1979, p. 11). Na segunda parte ele demonstra como surgiu o modo de produção capitalista e explica que "o capitalista é o dono dos meios de produção - edifícios, máquinas, matéria-prima etc.; compra a força de trabalho. É da associação dessas duas coisas que decorre a produção capitalista" (HUBERMAN, 1979, p. 168).

As considerações de HUBERMAN (1980), contribuem com o entendimento da questão quando analisa a transição do feudalismo para o capitalismo:

Poucos indícios há de que alguém devia produzir todas essas coisas, que armaduras não crescem em árvores, e que os alimentos, que realmente crescem, tem que ser plantados e cuidados. Mas assim é. (HUBERMAN, 1980, p. 11).

Enfatizando a questão ambiental no cerne desta discussão, a relação entre a problemática dos impactos ambientais e o sistema capitalista é intrínseca e pertinente. Segundo Burns (2001, p. 770), 
o pessimismo com relação à condição humana não se derivava apenas de preocupação com problemas contemporâneos (...). Originava-se também do medo do futuro - do futuro dos seres humanos, da própria terra e daquilo que se chama de sua ecologia (Burns, 2001, p. 770).

Burns (2001) em sua obra traz uma curta análise sobre as realizações e limitações da ciência e da tecnologia. Neste texto, menciona que a grandeza dos problemas tem deixado os intelectuais em dúvida:

A maioria daqueles a quem cabe a responsabilidade de encontrar soluções para os problemas - basicamente políticos e funcionários públicos -, mantém uma atitude de cauteloso otimismo. Em busca de soluções, voltam-se ainda, paradoxalmente, para aqueles mesmos setores responsáveis, em muitos casos, pela criação dos problemas: a ciência e a tecnologia. Foram os cientistas e os técnicos que inventaram e aperfeiçoaram o motor de combustão interna e o DDT. Agora outros cientistas e outros técnicos procuram meios de combater seus efeitos nocivos (BURNS, 2001, p. 773).

Neste contexto, cabe à ciência o papel de descortinar as causas dos problemas ocasionados pela humanidade, em busca de reflexão que irão originar possíveis soluções. No bojo desta discussão, o historiador torna-se relevante ao contribuir para o debate desta nova História global, interdisciplinar e que traz consigo novas considerações sobre o meio ambiente, em oposição à historiografia tradicional, que se ocupa em relatar o passado e transmitir os fatos de maneira científica e racional.

Ao analisar as condições impostas ao meio ambiente com o avanço do modelo capitalista em todos os segmentos, o desenvolvimento de novas tecnologias e os efeitos da explosão populacional decorrente do sistema de produção vigente, urge trazer à luz da História, nova perspectiva sobre o assunto em pauta - impacto ambiental - sua divulgação e interpretação, na tentativa de uma reflexão holística do social que estude com novos olhares a sociedade do mundo atual bem como das sociedades do passado.

Devido a isto, é importante que se conheça a História locorregional para que se reflita sobre os desdobramentos deste assunto em uma visão pontual do problema em questão. Desta forma, as análises apontadas por Leite (1981) em relação aos impactos ambientais na região do Pontal do Paranapanema são imprescindíveis para que se iniciem as discussões.

O autor em sua tese descreve minuciosamente a região do Pontal do Paranapanema, em uma visão histórica, geográfica, social, política, econômica e ambiental. Sua principal preocupação 
foi analisar como as questões de ordem política e econômica puderam interferir no meio ambiente de forma dramática e pontual.

Nesta região, o governo federal criou três reservas florestais, destinadas à preservação da biodiversidade regional. No entanto, a ocupação da região, realizada de forma desenfreada e desregulada culminou com a destruição total de duas destas reservas, restando somente na atualidade a conhecida como Parque Estadual Morro do Diabo, situado no município de Teodoro Sampaio-SP.

Isto se deu pela forma de ocupação e posterior exploração das terras devolutas, que envolveram todo tipo de arbitrariedade e violência no processo. Essas ocupações irracionais e irregulares provocaram mudanças irreparáveis que "acabaram por ferir fundo o meio ambiente; irregular também porque poucos se apoderaram de muito, enquanto muitos permaneceram sem nada". (LEITE, 1981, p. 10).

De acordo com o autor,

A multidão que chegava em busca de terras para plantar, pouco se importava se estas eram públicas, particulares, com titulação regular ou não. Uma distinção ficara patente: enquanto que as glebas ocupadas por particulares eram defendidas até a bala pelo seu ocupante maior e suposto proprietário, as do Estado foram vítimas de aventureiros grandes e pequenos que passaram a disputar, entre si, sortes de terras que não lhes pertenciam (LEITE, 1981, p. 71).

Somadas ao impacto ambiental ocasionado pelo processo de ocupação, novos empreendimentos fixam-se à região por encontrar terras a baixos preços e mão de obra barata. Foi o caso das usinas hidrelétricas e das usinas de açúcar e álcool. Para esta pesquisa, no entanto, o assunto em tela é a discussão sobre como a história vem divulgando e interpretando esses impactos ambientais. Nesta perspectiva, a pesquisa justifica-se por buscar compreender de que maneira as informações sobre impactos ambientais ocasionados pela instalação e funcionamento das usinas hidrelétricas e empreendimentos do agronegócio sucroalcooleiro na região do Pontal do Paranapanema são disseminadas na sociedade por meio das publicações científicas. Importa por tratar do assunto sob a ótica histórica, revelando como vem sendo realizada a interpretação do assunto. Por se tratar de uma discussão historiográfica, torna-se oportuna que ocorra no campo acadêmico, visto que, a região do Pontal do Paranapanema, amplamente estudada na perspectiva geográfica, política, social e econômica, poderá ser objeto de análises históricas relevantes na esfera ambiental. 
Assim, o principal objetivo deste trabalho é compreender de que forma vem sendo interpretada a história dos impactos ambientais gerados pelo avanço capitalista na região do Pontal do Paranapanema.

\section{METODOLOGIA}

A pesquisa será realizada utilizando-se de levantamento documental (de domínio público) sobre as três usinas hidrelétricas e as principais usinas de açúcar e álcool instaladas na região do Pontal do Paranapanema, no intuito de descrever um panorama e contextualizar, historicamente, a região no momento de suas instalações, levantando o que motivou a chegada destes empreendimentos e o impacto ocasionado por estas instalações. Pretende-se apresentar breve histórico regional de modo a proporcionar reflexão acerca do contexto histórico, social, econômico e ambiental da região, utilizando-se, para esta finalidade, de pesquisadores cujos trabalhos focaram as análises regionais face aos teóricos dos estudos históricos. Que esteja claro que não se trata apenas de um levantamento historiográfico sobre os impactos ambientais regionais, mas sim a compreensão de como esses impactos vem sendo tratados à luz da ciência histórica.

Para este texto que consiste em projeto do Curso de Mestrado em Meio Ambiente e Desenvolvimento Regional da Universidade do Oeste Paulista, vem sendo construída a base empírica realizando levantamento que tomou como ponto de partida trabalhos de conclusão de cursos de Mestrado e Doutorado da Universidade Estadual Paulista, Campus de Presidente Prudente e Rio Claro, e da Universidade de São Paulo, por estas instituições manterem vasto acervo publicado relacionado ao objeto de estudo deste trabalho.

Sob o aporte dessas considerações metodológicas tidas, pelas características da investigação, como adequadas à análise de que se ocupa esta pesquisa, busca-se compreender de que forma vem sendo contada a história dos impactos ambientais na região do Pontal do Paranapanema.

\section{RESULTADOS}

A preocupação em analisar de que forma os impactos ambientais são divulgados e interpretados pelos autores sugeridos para esta pesquisa foi a proposta deste trabalho. $\mathrm{O}$ recorte temporal escolhido a princípio - 1990 a 2000 - reflete sobre o funcionamento de empreendimentos que ocasionaram grande parte destes impactos: as três Usinas Hidrelétricas 
(Primavera, Rosana e Taquaruçu) e as usinas de açúcar e álcool. Esta periodização proposta visa facilitar as análises dos trabalhos.

A construção da base empírica deste trabalho vem sendo realizada por meio de busca de publicações em nível de Pós-Graduação, que permitiu apresentar neste texto cinco autores selecionados em razão das relevantes contribuições por eles apresentadas ao assunto em questão.

Foram selecionados para a análise, os seguintes autores: Leite (1981), Silveira (1990), Fernandes (1994), Hespanhol (2000) e Felício (2011). Apesar de anteceder à data proposta pelo estudo, o primeiro autor foi selecionado por ser a sua obra uma referência no que tange à pesquisa na região do Pontal do Paranapanema. Em sua tese de Livre-Docência, Leite (1981) conseguiu levantar o histórico da ocupação da região, descrevendo os mínimos aspectos geográficos até a relação do capital com a terra, e com quem nela habitava. Já Felício (2011) foi selecionado por trazer em seu estudo uma gama de autores clássicos, que se debruçaram sobre a questão do impacto ambiental na esfera mundial. Deste modo, justifica-se exceder o período de análise proposto inicialmente para este estudo.

\section{DISCUSSÃO}

A ocupação da região do Pontal do Paranapanema, analisada por Leite (1981) em sua tese de Livre-Docência apresenta vasto histórico de localização, povoamento e constituição das reservas florestais: a Lagoa São Paulo, a Grande Reserva do Pontal e a Reserva do Morro do Diabo. O povoamento da região se deu de forma irregular, na qual as terras destinadas à preservação ambiental acabaram nas mãos de grandes posseiros.

No processo de ocupação das terras, então reservadas, tudo era válido: o suborno de escrivães, juízes e promotores; o compadresco político e, eventualmente, o recurso as armas de grupos de jagunços a soldo dos interessados (LEITE, 1981, p. 8).

Ao tratar das reservas florestais, Leite (1981) relata as tentativas de ocupação das terras demarcadas para este fim. Menciona que até mesmo "forças políticas regionais começam a pressionar o governo estadual no sentido de extinguir a reserva" (LEITE, 1981, p. 79). No decorrer do trabalho, o autor aponta como essa ocupação desenfreada e irregular afetou o meio ambiente, e já nas considerações finais de sua tese, o autor aponta um panorama geral da situação na região na época, mencionando o impacto que estava sendo causado com a instalação da Usina Hidrelétrica de Porto Primavera: 
O imenso lago a ser formado pela Usina Hidrelétrica Porto Primavera cobrirá toda a área da Lagoa São Paulo situada a cerca de $140 \mathrm{~km}$ ao norte do complexo. As lagoas desaparecerão melancolicamente com as matas que rodeavam e as gerações futuras não saberão de sua existência (LEITE, 1981, p. 241).

A ocupação capitalista da região também é explorada em Silveira (1990), que trata da "Recriação capitalista do campesinato", abordando o histórico do processo de formação da estrutura fundiária em Presidente Prudente. Em sua tese, cujo recorte temporal é 1950 a 1985, a autora relata as relações capitalistas do trabalho no campo, abordando as condições do trabalho familiar e do colonato, e como os latifundiários exploravam esta mão de obra. Interessante analisar como as sucessões de culturas agropecuárias e transformações no modo de produção contribuíram para a valorização das terras.

De acordo com a autora, "nem todas as fazendas eram exploradas, muitos adquiriam terras e as mantinham como reserva de valor". (SILVEIRA, 1990, p. 45). Ao alcançar altos preços por serem intocadas, as áreas florestais eram subdivididas em lotes e vendidas, principalmente para a produção do café.

Tais características - fertilidade e localização - determinavam uma hierarquização entre as terras mais e menos adequadas à produção do café que se traduzia toda a mercantilização das terras, numa hierarquia correspondente de preços (SILVEIRA, 1990, p. 45).

Neste ritmo de ocupação, predominou a devastação ambiental:

Por volta de 1970, quase todo o desmatamento da região, principalmente do Pontal do Paranapanema, já estava efetuado, ultimando uma forma de arrendamento em que o grande grileiro subarrendava pequenas parcelas para os rendeiros e iniciava-se a derrubada da mata (SILVEIRA, 1990, p. 100).

Assim como Leite (1981), Silveira (1990) relata sobre a criação das três reservas florestais na região do Pontal do Paranapanema, e como foram pouco a pouco ocupadas. Menciona, também, sobre o impacto ambiental decorrente da instalação "das Usinas Hidrelétricas de Rosana, Porto Primavera e Taquaruçu, que deu origem aos projetos de reassentamento" (SILVEIRA, 1990, p. 86).

Tendo em vista esses aspectos e o propósito deste estudo, vale informar que a proposital organização das referências em ordem cronológica deu-se por ser haver percebido que os autores aqui apresentados complementam-se entre si, cada qual tratando da questão do impacto 
ambiental no seio de seus respectivos objetos de estudo. Esta breve explanação dos conteúdos reflete uma prévia de como a questão dos impactos ambientais na região do Pontal do Paranapanema vem sendo divulgada e interpretada.

\section{CONCLUSÃO}

As reflexões aqui apresentadas objetivaram compreender de que forma vem sendo interpretada a história dos impactos ambientais gerados pelo avanço capitalista na região do Pontal do Paranapanema. Os autores analisados apresentam valorosa contribuição para a formatação de uma base empírica ao trabalho, que juntamente com os teóricos da nova História, promovem terreno fértil para a discussão.

A contribuição de teóricos da História Ambiental e das Ciências Sociais, como Löwy (2005) traduz-se no pensamento de que as crises ecológicas oriundas do processo capitalista, e o colapso social, gerido no bojo da globalização, só serão remediados por meio de uma mudança de civilização, cultural e generalizada. O entendimento desta mudança se dará por meio do levantamento histórico do processo que desencadeou esta crise. Em âmbito regional, este processo traduz-se no avanço capitalista à região do Pontal do Paranapanema.

A forma como esta história vem sendo interpretada permite descrever não só o pensamento de um autor isoladamente, mas sim de uma parcela da sociedade, responsável por produzir e transmitir conhecimento. Estas implicações preocupam quando se reflete sobre o propósito da divulgação. A ciência não é imparcial, podendo servir tanto a propósitos desinteressados como ao próprio causador do problema. Grandes empresas capitalistas mantêm pesquisadores em seus quadros funcionais.

No caso da Ciência Histórica, a manipulação de fontes, muito comum no modelo tradicional, vem perdendo força, pois a própria cientificidade da História como disciplina foi amplamente questionada décadas atrás. Tais questionamentos proporcionaram emergir o paradigma vigente, que favorece a "História vista de baixo", promovendo também uma interpretação mais ampla dos fatos. É com esta visão que se pretende continuar as análises e descortinar de que forma os impactos ambientais vem sendo interpretados.

\section{REFERÊNCIAS}

BURNS, Edward McNall. História da Civilização Ocidental: do homem das cavernas às naves espaciais. v. 2. 40 ed. São Paulo: Globo, 2001. 
HESPANHOL, Rosângela Aparecida de Medeiros. Produção familiar: perspectivas de análise e inserção na microrregião geográfica de Presidente Prudente - SP. 2000. 354f. Tese (Doutorado em Geografia). Instituto de Geociências e Ciências Exatas, Universidade Estadual Paulista, Rio Claro.

HUBERMAN, Leo. Historia da Riqueza do Homem. 15 ed. Rio de Janeiro: Zahar, 1979.

LEITE, Antonio Ferrari. A ocupação do Pontal do Paranapanema. 1981. 256f. Tese (Livre-Docência em Geografia Regional). Instituto de Planejamento e Estudos Ambientais, Universidade Estadual Paulista, Presidente Prudente.

LÖWY, Michael. Ecologia e socialismo. São Paulo: Cortez, 2005. (Coleção Questões da Nossa Época; v. 125).

SILVEIRA, Fátima Rotundo da. A recriação capitalista do campesinato: os camponeses na região de Presidente Prudente. 1990. 255 f. Tese (Doutorado em Geografia). Departamento de Geografia. Universidade de São Paulo. São Paulo.

WEBER, Max. A ética protestante e o espírito do capitalismo. 11 ed. São Paulo: Pioneira, 1996. 